\title{
INDUKSI PLANLET ANGGREK CATTLYEA SP SECARA IN-VITRO PADA MEDIA MURASHIGE-SKOOG DAN BAHAN ORGANIK
}

\author{
Ida Royani \\ idaroyani@ikipmataram.ac.id
}

\begin{abstract}
Abstrak. Latar belakang dari penelitian ini mahalnya zat pengatur tumbuh sintetik yang menjadi salah satu penghalang dalam perbanyakan tanaman secara in-vitro. Penelitian ini bertujuan untuk mendapatkan formula yang tepat dengan penggunaan ekstrak wortel dan air kelapa (bahan organik) dalam induksi planlet anggrek Cattleya sp secara in-vitro. Penelitian ini dilakukan di Laboratorium Kultur Jaringan BBI-PPH Narmada Nusa Tenggara Barat. Penelitian dilaksanakan dengan menggunakan Rancangan Acak Kelompok (RAK) faktorial dengan dua faktor, masing masing faktor terdiri dari 3 level. Faktor 1, Konsentrasi Media MS (M) dengan 3 level: M1: MS Full; M2: 1/2 MS; M3: 1/4 MS. Faktor 2, Komposisi Bahan Organik (O) terdiri dari: O1: Ekstrak wortel $40 \mathrm{ml} / \mathrm{L}+$ Air kelapa $150 \mathrm{ml} / \mathrm{L}$; O2: Ekstrak wortel $50 \mathrm{ml} / \mathrm{L}$ + Air kelapa $200 \mathrm{ml} / \mathrm{L}$; O3: Ekstrak wortel $60 \mathrm{ml} / \mathrm{L}$ + Air kelapa $250 \mathrm{ml} / \mathrm{L}$. Hasil penelitian pada parameter jumlah daun terbanyak terdapat pada perlakuan MS full $+40 \mathrm{ml} / \mathrm{L}$ ekstrak wortel $+150 \mathrm{ml} / \mathrm{L}$ air kelapa dengan rata-rata 5,44 daun. Jumlah tunas terbanyak terdapat pada perlakuan $1 / 2 \mathrm{MS}+40 \mathrm{ml} / \mathrm{L}$ ekstrak wortel $+150 \mathrm{ml} / \mathrm{L}$ air kelapa dengan ratarata 3,49. Jumlah akar terbanyak terdapat pada perlakuan $1 / 2 \mathrm{MS}+40 \mathrm{ml} / \mathrm{L}$ ekstrak wortel $+150 \mathrm{ml} / \mathrm{L}$ air kelapa dengan rata-rata 12,06.
\end{abstract}

Kata Kunci: Induksi Planlet, MS, Bahan Organik, In-Vitro.

The background of this study is the high price of synthetic growth regulators which is one of the obstacles in plant propagation in vitro. This study aims to obtain the right formula by using carrot extract and coconut water (organic material) in the induction of Cattleya sp orchid plantlets in vitro. This research was carried out at the West Java West Nusa Tenggara BBI-PPH Network Culture Laboratory. The study was conducted using factorial randomized block design (RBD) with two factors, each factor consisting of 3 levels. Factor 1, MS (M) Media Concentration with 3 levels: M1: MS Full; M2: 1/2 ms; M3: 1/4 MS. Factor 2, Organic Composition (O) consists of: O1: Carrot Extract $40 \mathrm{ml} / \mathrm{L}+$ Coconut water $150 \mathrm{ml} / \mathrm{L}$; O2: Carrot extract $50 \mathrm{ml} / \mathrm{L}$ + Coconut water $200 \mathrm{ml} / \mathrm{L}$; O3: Carrot extract $60 \mathrm{ml} / \mathrm{L}+250 \mathrm{ml}$ coconut water / L. The results of research on the parameters of the most number of leaves found in the treatment of MS full $+40 \mathrm{ml} / \mathrm{L}$ carrot extract $+150 \mathrm{ml} / \mathrm{L}$ coconut water with an average of 5.44 leaves. The highest number of shoots was found in the treatment of $1 / 2 \mathrm{MS}+40 \mathrm{ml} / \mathrm{L}$ carrot extract $+150 \mathrm{ml} / \mathrm{L}$ coconut water with an average of 3.49. The highest number of roots was found in the treatment of $1 / 2 \mathrm{MS}+40 \mathrm{ml} / \mathrm{L}$ carrot extract $+150 \mathrm{ml} / \mathrm{L}$ coconut water with an average of 12.06 .

Keywords: Planlet Induction, MS, Organic Material, In-Vitro

\section{PENDAHULUAN}

Anggrek Cattleya merupakan anggrek yang memiliki harga relatif mahal jika dibandingkan dengan anggrek jenis lain, karena budidayanya sampai menghasilkan bunga membutuhkan waktu yang relatif lama, biaya produksi yang tinggi yang disebabkan karena penggunaan media tanam secara in-vitro

Jurnal Ilmiah Mandala Education menggunakan zat pengatur tumbuh sintetik yang harganya cukup mahal. Sehingga penggunaan alternatif media dasar menggunakan bahan organik mudah di dapat dengan harga yang lebih murah untuk menekan biaya produksi secara in-vitro. Ekstrak bahan organik alami seperti wortel dan air kelapa merupakan contoh yang digunakan dalam 
media perbanyakan in-vitro (Parera, 1997). Wortel merupakan salah satu sayuran yang kaya akan vitamin A karena mengandung pigmen karotenoid sebesar $8285 \mu \mathrm{g} / 100 \mathrm{~g}$, selain itu juga mengandung tiamin, riboflavin, piridoksin, dan vitamin-vitamin lainnya. Air kelapa banyak mengandung unsur hara, vitamin, gula, mineral dan zat pengatur tumbuh. Air kelapa banyak digunakan dalam perbanyakan in-vitro karena memiliki kandungan sitokinin alami yang tinggi berupa zeatin dan ribozeatin dan IAA (Indole Acetic Acid). Air kelapa juga dapat menstimulir proses diferensiasi dan merangsang pembelahan sel (Widiastoety, 2010).

Perbanyakan secara konvensional sangat sulit untuk memenuhi kebutuhan bibit yang sangat banyak dalam waktu relatif cepat. Bibit yang dihasilkan sedikit, tidak seragam dan kesehatanya tidak terjamin.. Mungkin hal inilah yang mendasari spesies anggrek ini menjadi salah satu plasma nutfah yang dilindungi. Selain itu informasi dan laporan hasil penelitian mengenai spesies dan varian anggrek Cattleya $s p$ masih jarang sehingga perlu penelitian lebih lanjut. Oleh karena itu, salah satu alternatif untuk pemecahan masalah itu adalah dengan menggunakan metode kultur in-vitro yang dikenal dengan metode kultur jaringan sehingga pemenuhan kebutuhan bibit tanaman anggrek akan dapat dihasilkan dengan jumlah banyak (Isda dan fatonah, 2014).

\section{METODE}

Penelitian dilaksanakan di laboratorium kultur jaringan BBI-PPH Narmada dari bulan januari 2019 sampai mei 2019 Penelitian dilaksanakan dengan menggunakan Rancangan Acak Kelompok (RAK) faktorial dengan dua faktor, masing masing faktor terdiri dari 3 level. Faktor 1, Konsentrasi Media MS (M) dengan 3 level: M1: MS Full; M2: 1/2 MS; M3: 1/4 MS. Faktor 2, Komposisi Bahan Organik (O) terdiri dari: O1: Ekstrak wortel $40 \mathrm{ml} / \mathrm{L}+$ Air kelapa $150 \mathrm{ml} / \mathrm{L}$; O2: Ekstrak wortel $50 \mathrm{ml} / \mathrm{L}+$ Air kelapa $200 \mathrm{ml} / \mathrm{L}$; O3: Ekstrak wortel $60 \mathrm{ml} / \mathrm{L}$ + Air kelapa $250 \mathrm{ml} / \mathrm{L}$. Masing-masing perlakuan diulang sebanyak 3 kali ulangan. Jika hasil menunjukkan nilai berbeda nyata maka akan dilanjutkan dengan uji Duncan's Multiple Range Test (DMRT) pada taraf 5\%. (Tanujaya, 2013). Rancangan percobaan disajikan dalam Tabel 1

Tabel 1. Rancangan percobaan induksi akar anggrek Cattleya $s p$

\begin{tabular}{|l|c|c|}
\hline $\begin{array}{c}\text { Murashing-Skoog } \\
\text { (MS) ml/L }\end{array}$ & $\begin{array}{c}\text { Ekstrak Wortel } \\
\mathrm{ml} / \mathrm{L}\end{array}$ & $\begin{array}{c}\text { Air Kelapa } \\
\mathrm{ml} / \mathrm{L}\end{array}$ \\
\hline Full & 40 & 150 \\
\hline $1 / 2$ & 50 & 200 \\
\hline $1 / 4$ & 60 & 250 \\
\hline
\end{tabular}

Keterangan :

$$
\mathrm{M}_{1}=\text { full MS } \quad \mathrm{O}_{1}=\text { ekstrak wortel }
$$

$40 \mathrm{ml} / \mathrm{L}$ + air kelapa $150 \mathrm{ml} / \mathrm{L}$

$$
\mathrm{M}_{2}=1 / 2 \mathrm{MS} \quad \mathrm{O}_{2}=\text { ekstrak wortel }
$$

$50 \mathrm{ml} / \mathrm{L}$ + air kelapa $200 \mathrm{ml} / \mathrm{L}$

$$
\mathrm{M}_{3}=1 / 4 \mathrm{MS} \quad \mathrm{O}_{3}=\text { ekstrak wortel }
$$
$60 \mathrm{ml} / \mathrm{L}$ + air kelapa $250 \mathrm{ml} / \mathrm{L}$

\section{HASIL DAN PEMBAHASAN}

Berdasarkan hasil pengamatan dari penelitian yang di lakukan mulai dari tanggal 20 Januari sampai 26 Mei 2019. Anggrek catlyea sp yang digunakan dalam penelitian ini adalah anggrek yang di ambil dari timba nuh (tempat pariwisata lombok tengah) melalui biji yang di induksi pada media Murashing-Skoog (MS) selama 8 minggu kemudian di induksi ke media perlakuan. Hasil penelitian induksi anggrek Catlyea sp pada perlakuan dapat dilihat pada Tabel 2.

Tabel 2 Hasil penelitian induksi planlet anggrek Catlyea sp pada media MS dan bahan oerganik

\begin{tabular}{|l|l|l|l|}
\hline Perlakuan & $\begin{array}{l}\text { Jumlah Daun } \\
\text { (Rata-rata) }\end{array}$ & $\begin{array}{l}\text { Jumlah Tunas } \\
\text { (Rata-rata) }\end{array}$ & $\begin{array}{c}\text { Jumlah Akar } \\
\text { (Rata-rata) }\end{array}$ \\
\hline $\mathrm{M}_{1} \mathrm{O}_{1}$ & 5,44 & 2,32 & 6,40 \\
\hline $\mathrm{M}_{1} \mathrm{O}_{2}$ & 4,35 & 1,05 & 4,03 \\
\hline $\mathrm{M}_{1} \mathrm{O}_{3}$ & 4,21 & 2,01 & 4,00 \\
\hline $\mathrm{M}_{2} \mathrm{O}_{1}$ & 4,39 & 3,00 & 12,06 \\
\hline $\mathrm{M}_{2} \mathrm{O}_{2}$ & 3,06 & 1,02 & 8,32 \\
\hline $\mathrm{M}_{2} \mathrm{O}_{3}$ & 3,01 & 1,35 & 6,04 \\
\hline $\mathrm{M}_{3} \mathrm{O}_{1}$ & 4,39 & 1,01 & 12,00 \\
\hline $\mathrm{M}_{3} \mathrm{O}_{2}$ & 2,06 & 1,00 & 6,07 \\
\hline $\mathrm{M}_{3} \mathrm{O}_{3}$ & 3,00 & 1,00 & 9,45 \\
\hline
\end{tabular}

Berdasarkan Tabel 2 diperoleh hasil penelitian pada parameter jumlah daun terbanyak pada konsentrasi MS full $+40 \mathrm{ml} / \mathrm{L}$ ekstrak wortel $+15 \mathrm{ml} / \mathrm{L}$ air kelapa. Jumlah tunas terbanyak pada konsentrasi $1 / 2 \mathrm{ml} / \mathrm{L} \mathrm{MS}$ + $50 \mathrm{ml} / \mathrm{L}$ ekstrak wortel $+200 \mathrm{ml} / \mathrm{L}$ air kelapa. Jumlah akar terbanyak pada konsentrasi 
1/2ml/L MS + $50 \mathrm{ml} / \mathrm{L}$ ekstrak wortel +200 $\mathrm{ml} / \mathrm{L}$ air kelapa dan $1 / 4 \mathrm{ml} / \mathrm{L} \mathrm{MS}+60 \mathrm{ml} / \mathrm{L}$ ekstrak wortel $+250 \mathrm{ml} / \mathrm{L}$ air kelapa. Panjang akar terpanjang pada konsentrasi $1 / 4 \mathrm{ml} / \mathrm{L}$ MS + $60 \mathrm{ml} / \mathrm{L}$ ekstrak wortel $+250 \mathrm{ml} / \mathrm{L}$ air kelapa. Hasil penelitian dapat dilihat pada gambar 1 .

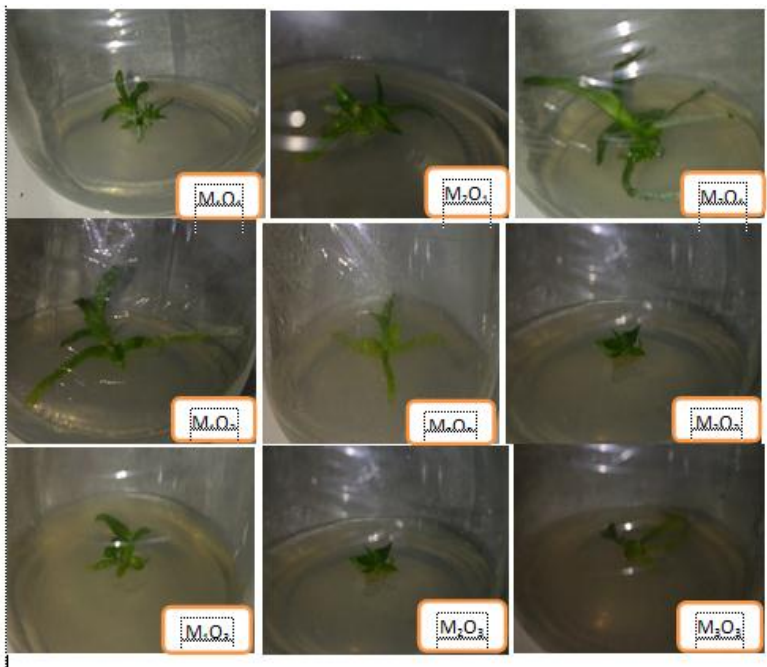

Gambar 1. Hasil Penelitian Induksi Planlet Anggrek Cattleya sp Pada Media MS dan Bahan Organik.

\section{Jumlah Daun}

Daun merupakan salah satu organ vegetatif yang sangat vital peranannya bagi kelangsungan hidup tanaman. Pada daun terdapat bagian yang sangat penting sehingga jumlah daun akan mempengaruhi kualitas hidup tanaman. Didalam daun terdapat kloroplas yang berfungsi untuk fotosintesis yaitu proses pembuatan makanan yang akan di salurkan keseluruh bagian tumbuhan melalui pembuluh pengangkut (Lakitan, 2000). Rata-rata jumlah daun terbanyak terdapat pada perlakuan MS full $+40 \mathrm{ml} / \mathrm{L}$ ekstrek wortel $+150 \mathrm{ml} / \mathrm{L}$ air kelapa dengan rata-rata sebanyak 5,44 ini. Media MS full mendorong pertumbuhan dan perkembangan dengan cepat karena memiliki kandungan yang tepat untuk kebutuhan tanaman, selain itu media MS juga kaya akan kandungan unsur hara. Hendaryono (2000) menyatakan bahwa unsur mineral seperti $\mathrm{Ca}$, $\mathrm{P}, \mathrm{Fe}$, vitamin $\mathrm{C}$, niacin, dan tiamin berperan dalam merangsang pertumbuhan jumlah daun. Selain itu, menurut Widiastoety dan Bahar,
(1995) menyebutkan bahwa pemberian sukrosa, fruktosa, glukosa dam gula sebagai sumber karbohidrat memberikan hasil yang baik bagi jumlah daun.

\section{Jumlah Tunas}

Dari hasil pengamatan jumlah tunas terbanyak terdapat pada perlakuan $1 / 2 \mathrm{MS}+40$ $\mathrm{ml} / \mathrm{L}$ ekstrak wortel $+150 \mathrm{ml} / \mathrm{L}$ air kelapa dengan rata-rata tunas 3,49. Air kelapa yang disubtitusi pada media kultur akan meningkatkan pertumbuhan tunas tanaman krisan dan anggrek ( Matatula (2003). Penggunaan media $1 / 2$ MS baik digunakan sebagai media dasar karena media $1 / 2 \quad$ MS mengandung hara makro dan mikro seperti cobalt $(\mathrm{Co})$, tembaga $(\mathrm{Cu})$, seng $(\mathrm{Zn})$, boron (B), dan molybdenum (Mo) yang tidak terdapat pada media Knudson $\mathrm{C}$ dan Vacin Went. Media 1/2 MS juga mengandung myoinositol dalam jumlah yang cukup besar (100 mg/l) (Yusnita, 2004). Zulkarnain (2009), secara umum dapat dikatakan auksin biasanya meningkatkan inisiasi akar sedangkan sitokinin meningkatkan proliferasi pucuk. Dalam penelitian ini ekstrak wortel dan air kelapa berperan sebagai auksin dan sitokinin sehingga ada perbedaan yang signifikan pada semua perlakuan. Hal ini menunjukkan bahwa dalam pembentukan tunas dibutuhkan zat pengatur tumbuh golongan sitokinin yang efektif untuk menginduksi tunas. Hasil ini sejalan dengan penelitian Ugandhar et al. (2011) yang berhasil menginduksi tunas pada eksplan kotiledon dan hipokotil tanaman Cucumis sativus menggunakan sitokinin dengan konsentrasi $1 \mathrm{mg} / \mathrm{L}$ sampai $3 \mathrm{mg} / \mathrm{L}$.

\section{Jumlah akar}

Akar merupakan organ vegetatif tumbuhan yang mempunyai struktur luar yang terdiri dari daerah pertumbuhan akar, tudung akar, serta bulu akar dan berfungsi sebagai penyerap air dan unsur hara dari tanah menuju keseluruh bagian tumbuh-tumbuhan. Jumlah akar pada tanaman mengindikasikan seberapa luas jangkauan tanaman dalam menyerap nutrisi dan unsur hara. Semakin banyak jumlah akar semakin luas jangkauan tanaman 
tersebut dan semakin banyak nutrisi dan unsur hara yang diserap (Latifah dkk, 2017). Jumlah akar terbanyak terdapat pada perlakuan 1/2 MS + 40 ekstrak wortel + 150 air kelapa dengan rata-rata 12,06 dan perlakuan 1/4 MS + 40 ekstra wortel +150 air kelapa dengan rata-rata jumlah akar 12,00. Kandungan sitokinin yang terdapat dalam air kelapa juga memiliki peran dalam pembentukan akar. Hal ini didukung oleh pendapat Yong et al. (2009), bahwa sitokinin yang terkandung dalam air kelapa mempunyai kemampuan mendorong terjadinya pembelahan sel dan diferensiasi jaringan terutama dalam pembentukan tunas dan pembentukan akar. sitokinin dan auksin yang terkandung dalam ekstrak wortel dan air kelapa juga berinteraksi dengan konsentrasi yang terkandung dalam Media 1/2 dan 1/4 MS. Pertumbuhan akar terjadi pada saat tanaman telah berkembang lengkap sehingga auksin endogen yang berperan dalam pembentukan akar telah tersintesis pada pembentukan pucuk dan terakumulasi pada daerah pangkal tunas (Maninggolang dkk, 2018).

\section{DAFTAR PUSTAKA}

Hendaryono, D. P. S. (2000). Pembibitan anggrek dalam botol. Kanisius.

Latifah, T. suhermiafin, T. ermawati, N. 2017. Optimasi Pertumbuhan Planlet Cattleya Melalui Kombonasi Kekuatan Media Mirashige-Skoog Dan Bahan Organik. journal of applied agricultural suences, vol, 1. no, 1: 5462

Maninggolang, A. Mandang. Tilar. 2018. Pengaruh BAP dan Air Kelapa Terhadap Pertumbuhan Tunas Pucuk Dan Kandungan Sulforafan Brokoli (Brassica Oleracea L. Var Italia Plenek) Secara In-Vitro. journal agrisusio ekonomi unsrat, ISSN 19074298. vol, 1. hal 585-596.

Matatula, A. J. (3003). Subtitusi Media MS dengan Air Kelapa dan Gandasil-D Pada Kultur Jaringan Krisan. Eugenia 9 (4) : 203-211
Yong, J. W. H., Ge, L., Ng, Y. F., \& Tan, S. N. (2009). The chemical composition and biological properties of coconut (Cocos nucifera L.) water. Molecules, 14(12), 5144-5164. https://doi.org/10.3390/ molecules14125144

Yusnita. (2004). Kultur Jaringan. Cara Memperbanyak Tanaman secara Efisien. Jakarta.: Agromedia Pustaka.

Widiastoety, D., \& Bahar, F. A. (1995). Pengaruh berbagai sumber dan kadar karbohidrat terhadap pertumbuhan plantlet anggrek dendrobium. J. Hort, 5(3), 76-80.

Zulkarnain. 2009. Kultur Jaringan tanaman. Jakarta: PT Bumi Aksara 